\title{
Simulation of the Ill-Posed Problem of Reinforced Concrete Corrosion Detection Using Boundary Element Method
}

\author{
Syarizal Fonna, ${ }^{1}$ Israr M. Ibrahim, ${ }^{2}$ M. Ridha, ${ }^{1}$ Syifaul Huzni, ${ }^{1}$ and A. K. Ariffin ${ }^{3}$ \\ ${ }^{1}$ Department of Mechanical Engineering, Syiah Kuala University, Jalan Tgk Syech Abdul Rauf 7, Banda Aceh 23111, Indonesia \\ ${ }^{2}$ Tsunami \& Disaster Mitigation Research Center (TDMRC), Syiah Kuala University, Jalan Tgk Abdul Rahman, Gp. Pie, \\ Meuraxa District, Banda Aceh 23111, Indonesia \\ ${ }^{3}$ Department of Mechanical and Materials Engineering, Universiti Kebangsaan Malaysia, 43600 Bangi, Selangor, Malaysia
}

Correspondence should be addressed to Syarizal Fonna; syarizal.fonna@unsyiah.ac.id

Received 21 January 2016; Accepted 24 March 2016

Academic Editor: Jerzy A. Szpunar

Copyright (C) 2016 Syarizal Fonna et al. This is an open access article distributed under the Creative Commons Attribution License, which permits unrestricted use, distribution, and reproduction in any medium, provided the original work is properly cited.

\begin{abstract}
Many studies have suggested that the corrosion detection of reinforced concrete (RC) based on electrical potential on concrete surface was an ill-posed problem, and thus it may present an inaccurate interpretation of corrosion. However, it is difficult to prove the ill-posed problem of the RC corrosion detection by experiment. One promising technique is using a numerical method. The objective of this study is to simulate the ill-posed problem of RC corrosion detection based on electrical potential on a concrete surface using the Boundary Element Method (BEM). BEM simulates electrical potential within a concrete domain. In order to simulate the electrical potential, the domain is assumed to be governed by Laplace's equation. The boundary conditions for the corrosion area and the noncorrosion area of rebar were selected from its polarization curve. A rectangular reinforced concrete model with a single rebar was chosen to be simulated using BEM. The numerical simulation results using BEM showed that the same electrical potential distribution on the concrete surface could be generated from different combinations of parameters. Corresponding to such a phenomenon, this problem can be categorized as an ill-posed problem since it has many solutions. Therefore, BEM successfully simulates the ill-posed problem of reinforced concrete corrosion detection.
\end{abstract}

\section{Introduction}

Rebar corrosion is one of the main causes of reinforced concrete (RC) premature failures [1-3]. Reports of these premature failures can be found in various publications. The failures include the collapse of Silver Bridge in USA, 1967 [4], the collapse of highway overpass in Canada, 2006 [5], and the collapse of Atlantis Water Adventure, Taman Impian Jaya Ancol in Indonesia, 2011 [6]. Recent failure due to corrosion was reported in March 2015: the porch of a building collapsed in Albany, USA [7]. Thus, It is important to conduct periodic evaluation, monitoring and early detection for RC corrosion [8-10].

The half-cell potential technique is among the conventional methods that are used in the field to detect or evaluate the RC corrosion [11, 12]. This technique follows the procedure as described in ASTM C876 to evaluate corrosion of an RC structure. However, the method only provides the probability of corrosion $[13,14]$ and needs a considerable amount of measurement data to generate an accurate potential map [11, 15]. Therefore, it is important to understand the nature of the RC corrosion problem before the development of other methods and/or improvement of conventional techniques to detect RC corrosion. Many workers have proposed methods based on inverse analysis to detect $\mathrm{RC}$ corrosion $[13,15,16]$ since the nature of $\mathrm{RC}$ corrosion implies an ill-posed problem. However, it is difficult to prove the ill-posed problem of RC corrosion via experiments. Thus, using a numerical method to prove the ill-posed problem of $\mathrm{RC}$ corrosion is very promising.

Many researchers have explored a numerical method termed the Boundary Element Method (BEM) to simulate the corrosion phenomenon. The corrosion was modeled by the Laplace equation in BEM [16-18]. Thus, BEM can potentially 
be utilized to simulate the ill-posed problem of RC corrosion. The purpose of this paper is to simulate the ill-posed problem of RC corrosion problem by using BEM.

\section{Basic Idea to Simulate the Ill-Posed Problem of RC Corrosion}

The ill-posed problem is a problem that has one of the following criteria; that is, the problem has no unique solution or many solutions, and small error would give high disturbance to the solution [19]. The motivation for utilizing BEM to simulate the ill-posed problem of RC corrosion came from the actual condition that interpretation of the half-cell potential technique is merely based on electrical potential data on the RC surface, as mentioned in ASTM C876. Previous researchers have pointed out that the electrical potential on the RC surface is influenced not only by rebar corrosion but also by other parameters [20].

Furthermore, it has been suggested that the variation of some parameters could give similar electrical potential profiles on the RC surface, which should indicate an illposed problem. By simulating similar electrical potentials resulting from different parameter combinations, the illposed problem of RC corrosion can be proven. This illposed problem might lead to misleading conclusions in the detection of RC corrosion by the half-cell potential technique.

Since BEM has the capability of obtaining electrical potential and current density within an evaluated domain, it is proposed in this paper that BEM is also capable to be used to simulate the ill-posed problem of RC corrosion. The basic idea for this purpose was to compare the electrical potential on an RC surface obtained by BEM, which came from various combinations of parameters.

\section{RC Corrosion Modeling in BEM}

The RC model with single reinforcing steel as given in Figure 1(a) was considered. There is corrosion located in the reinforcing steel. This RC model was simplified into a $2 \mathrm{D}$ model, as shown in Figure 1(b), which also displays the boundary conditions for the model.

In developing BEM for RC corrosion simulation, the electrical potential field $(\phi)$ within the whole RC domain $(\Omega)$ is mathematically governed by the Laplace equation as given in $[17,18,21]$

$$
\nabla^{2} \phi=0 \quad \text { in } \Omega
$$

The relationship between electrical potential and current density (i) for the domain should follow $[21,22]$

$$
i=-\kappa \frac{\partial \phi}{\partial \mathbf{n}}\left(\mathrm{A} / \mathrm{m}^{2}\right)
$$

where $\kappa$ is the concrete conductivity, $\mathbf{n}$ is the outward normal unit, and $\partial / \partial \mathbf{n}$ is the derivative in the normal direction.

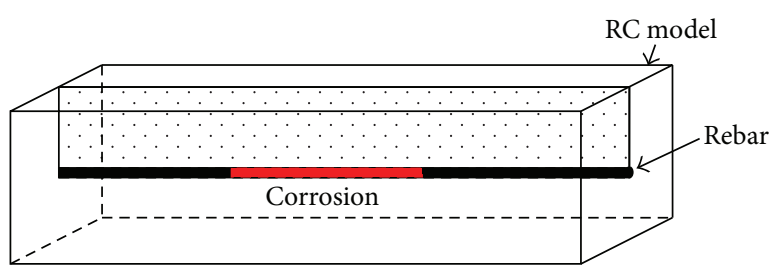

(a)

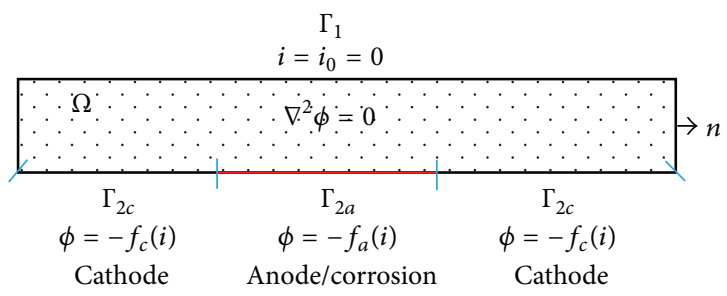

(b)

FIGURE 1: (a) RC model with single rebar; (b) 2D model of RC for BEM simulation.

The boundary conditions for the RC model are given in Figure $1(\mathrm{~b})$ and are written as

$$
\begin{aligned}
& i=i_{0}=0\left(\mathrm{~A} / \mathrm{m}^{2}\right) \quad \text { on } \Gamma_{1} \\
& \phi=-f_{a}(i)(\mathrm{V}) \quad \text { on } \Gamma_{2 a} \\
& \phi=-f_{c}(i)(\mathrm{V}) \quad \text { on } \Gamma_{2 c},
\end{aligned}
$$

where $i$ on the concrete surface $\left(\Gamma_{1}\right)$ is constant and is considered equal to zero, due to the low conductivity of concrete. $\phi$ on any point of the rebar or reinforcing steel $\left(\Gamma_{2}\right)$ is given by a function of $i$ that is generated from the polarization curve, that is, $f_{a}(i)$ for the corroded part (anode) and $f_{c}(i)$ noncorroded part (cathode) areas. The polarization curve was measured experimentally.

$\mathrm{BEM}$ is formulated to solve the RC model; hence, the electrical potential and current density on concrete and rebar surfaces can be obtained. The procedure of BEM formulation for the RC corrosion case can be found in [21].

\section{Numerical Simulation and Discussion}

In order to simulate the ill-posed problem of $\mathrm{RC}$ corrosion detection using BEM, an RC model was considered, as given in Figure 2. The model consists of a single rebar and corrosion. The corrosion size and rebar length, respectively, were $c \mathrm{~cm}$ and $50 \mathrm{~cm}$. The concrete cover depth for the model was $t \mathrm{~cm}$, while concrete conductivity for the model was $\kappa \Omega^{-1} \cdot \mathrm{m}^{-1}$. The boundary conditions for the model were the same as those already stated. The polarization curve for anode and cathode was obtained from $[15,23]$.

Ten combinations of parameters were selected for the simulation using BEM. Those parameters were corrosion size $(c)$, concrete cover $(t)$, concrete conductivity $(\kappa)$, and corrosion intensity at the anode part of rebar that was generated from polarization curves of the rebar in concrete. The combinations of parameters are listed in Table 1. For all 
TABLE 1: 10 combinations of parameters for evaluating the nature of the RC corrosion detection problem.

\begin{tabular}{lcccc}
\hline $\begin{array}{l}\text { Parameter } \\
\text { combinations }\end{array}$ & $\begin{array}{c}\text { Corrosion size }(c), \\
\mathrm{cm}\end{array}$ & $\begin{array}{c}\text { Concrete cover }(t), \\
\mathrm{cm}\end{array}$ & $\begin{array}{c}\text { Concrete conductivity } \\
(\kappa), \Omega^{-1} \cdot \mathrm{m}^{-1}\end{array}$ & $\begin{array}{c}\text { Corrosion } \\
\text { intensity, V } \\
(\text { versus SCE) }\end{array}$ \\
\hline 1 & 6 & 5 & 0.007 & $\phi_{a 1}=0.6-10 i$ \\
2 & 10 & 5 & 0.007 & $\phi_{a 1}=0.6-10 i$ \\
3 & 14 & 5 & 0.007 & $\phi_{a 1}=0.6-10 i$ \\
4 & 6 & 5 & 1 & $\phi_{a 1}=0.6-10 i$ \\
5 & 6 & 5 & 0.1 & $\phi_{a 1}=0.6-10 i$ \\
6 & 6 & 5 & 0.01 & $\phi_{a 1}=0.6-10 i$ \\
7 & 6 & 1 & 0.007 & $\phi_{a 1}=0.6-10 i$ \\
8 & 6 & 10 & 0.007 & $\phi_{a 1}=0.6-10 i$ \\
9 & 6 & 5 & 0.007 & $\phi_{a 2}=0.5-10 i$ \\
10 & 6 & 5 & 0.007 & $\phi_{a 3}=0.4-10 i$ \\
\hline
\end{tabular}

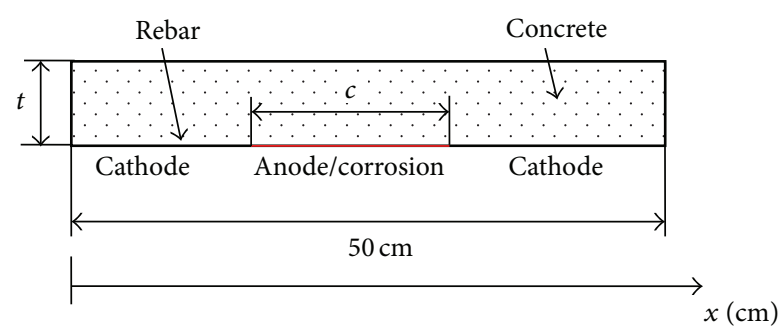

Figure 2: RC model for evaluating the nature of RC corrosion detection problem.

combinations, the cathode part of rebar was represented by its polarization curve in

$$
\phi_{c}=0.27-10 i(\mathrm{~V}) \text { versus SCE. }
$$

BEM was applied to simulate the electrical potential on the surface of RC for 10 combinations of parameters in Table 1. The simulation result is given in Figure 3, which shows the electrical potential profile on the RC surface for all parameter combinations. It shows that the electrical potential is generally higher above the corroded part than the cathode part.

Figure 4 shows how the corrosion size would affect the electrical potential profile on RC surface. Figure 4 also shows that the larger corrosion size would give a higher electrical potential on the RC surface. Also, the peak of the electrical potential profile becomes wider for larger corrosion size. Corresponding to half-cell potential technique, higher electrical potential on the RC surface means higher corrosion risk. It can be said that combination number 3 had a higher corrosion risk than combination numbers 1 and 2 . This might mislead corrosion evaluation, because even though the corrosion size of combination number 3 was larger than others, the corrosion rate for both could still be similar, since they both had same corrosion intensity, as given in Table 1. Also, the boundary conditions for the cathode part were similar for all combinations.
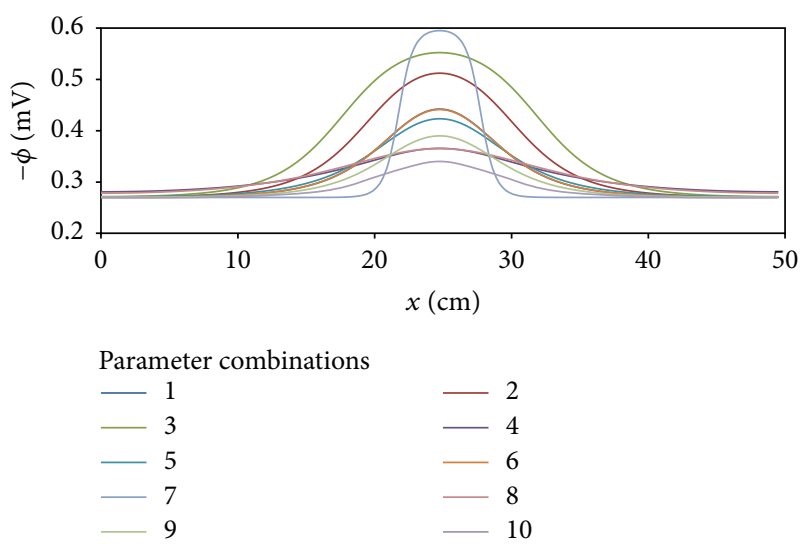

FIgURE 3: Electrical potential profiles on concrete surface for all combinations of parameters.

The electrical potential profiles on the RC surface were influenced by concrete conductivity, as shown in Figure 5. It shows that the electrical potential profile will flatten by increasing conductivity of concrete. This characteristic is consistent with the investigation that was conducted by PourGhaz et al. [20]. The phenomenon can also lead to misleading corrosion evaluation using the half-cell potential technique based on ASTM C876. For example, using combination number 6 will result in classifying the corrosion as severe corrosion risk level $(<-380 \mathrm{mV}$ versus SCE), while combination number 4 falls into the high corrosion risk level $(-380$ to $-230 \mathrm{mV}$ versus CSE) for the same corrosion. However, the actual corrosion for the combination was the same, that is, in terms of size and intensity.

Figure 6 shows the influence of concrete cover depth to electrical potential on the surface of concrete. The electrical potential above the corroded part would decrease by increasing the depth of concrete cover for the same corrosion. It was also similar to the work of Pour-Ghaz et al. [20]. Thus, similar to other parameters, the cover depth must be included in the analysis for detecting corrosion risk level based on ASTM 


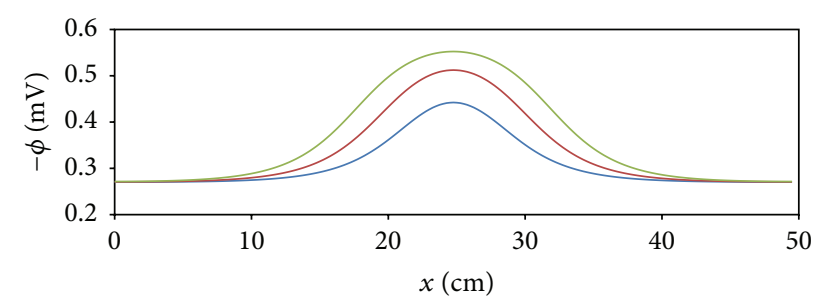

Parameter combinations

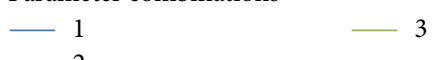

FIGURE 4: Electrical potential profiles on concrete surface for different corrosion sizes.

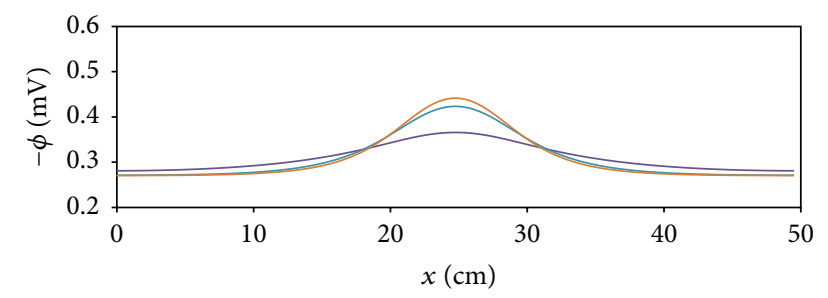

Parameter combinations

$-4-6$

FIGURE 5: Electrical potential profile on concrete surface for different concrete conductivities.

C876, in order to eliminate false positives and negatives in interpretation of electrical potential data.

Moreover, the corrosion intensity would affect the electrical potential of the concrete surface above the corroded rebar part, as shown in Figure 7. It shows that the higher corrosion intensity would bring higher electrical potential values on the concrete surface above the corroded part for the same corrosion size. This could be true, because higher corrosion intensity might lead to higher corrosion rate, and thus the electrical potential should be higher too.

By comparing electrical potential profiles for all parameter combinations, it was found that some profiles are similar, as given in Figure 8. This figure shows that electrical potential on the concrete surface for combination number 1 was almost similar to combination number 6 , and combination number 4 was almost identical to combination number 8 . This suggests that there exist combinations of parameters that may give the same electrical potential profile on the concrete surface.

From the presented results, it can be concluded that there are many solutions for the rebar corrosion problem. It has been shown that several similar electrical potential profiles on the concrete surface can be generated from several combinations of parameters. Therefore, it would be difficult to evaluate actual rebar corrosion only by using electrical potential data on the concrete surface based on ASTM C876.

According to Kabanikhin [19], such a phenomenon was categorized into an ill-posed problem. The conventional method, such as direct method, is insufficient to solve the problem. One promising method to solve the ill-posed problem is inverse analysis [24]. Several researchers have explored

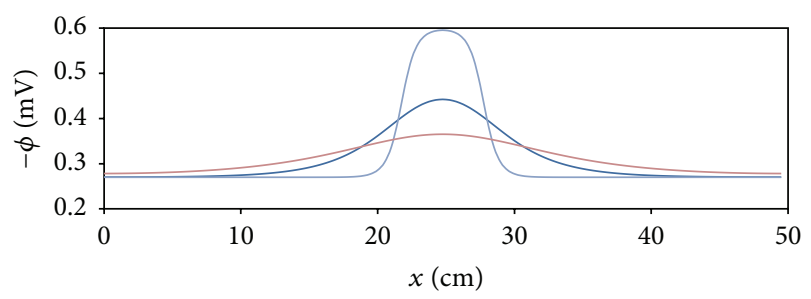

Parameter combinations

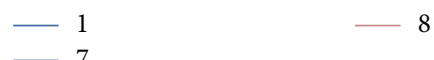

FIGURE 6: Electrical potential profile on concrete surface for different concrete cover depths.

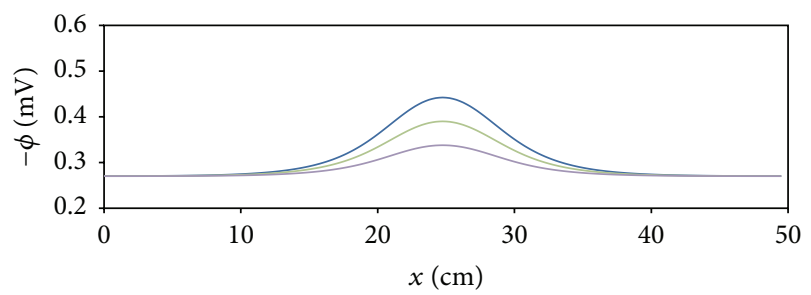

Parameter combinations

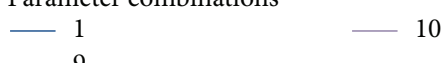

FIGURE 7: Electrical potential profile on concrete surface for different corrosion intensities.

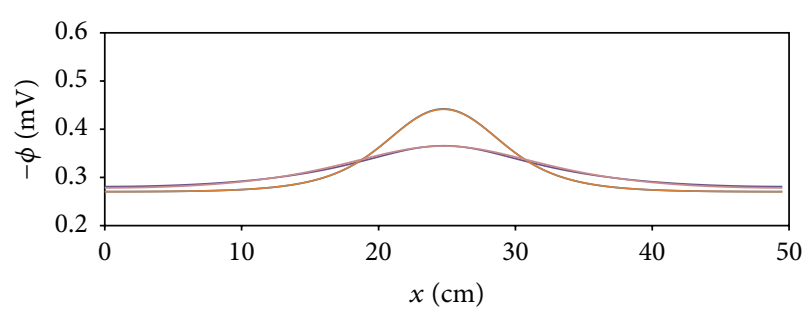

Parameter combinations

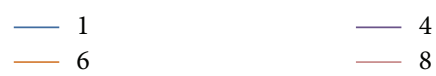

FIgURE 8: Electrical potential profile on concrete surface, showing that combination 1 is similar to 6 and that 4 is similar to 8 .

the application of inverse analysis to solve the rebar corrosion detection in concrete $[13,16,21,22]$, and the method has the potential to be applied in solving the RC corrosion detection problem.

\section{Conclusions}

The simulation of the ill-posed problem of rebar corrosion detection using the Boundary Element Method (BEM) has been presented in this paper. BEM was used to simulate electrical potential within concrete domain, especially on the concrete surface. The numerical simulation results with 10 parameter combinations showed that the electrical potential on the RC surface was not solely influenced by corrosion, but also by other parameters, such as concrete conductivity 
and cover depth. Furthermore, some combination of parameters might give the same electrical potential profile on the concrete surface. This phenomenon is categorized as an illposed problem, since there exist many solutions to the problem. Therefore, the detection of rebar corrosion using only electrical potential data on the concrete surface, as suggested in ASTM C876, might mislead corrosion evaluation due to the ill-posedness of the problem.

\section{Competing Interests}

The authors declare that they have no competing interests.

\section{References}

[1] H. A. Elfergani, R. Pullin, and K. M. Holford, "Damage assessment of corrosion in prestressed concrete by acoustic emission," Construction and Building Materials, vol. 40, pp. 925933, 2013.

[2] G. Qiao, T. Liu, Y. Hong, and J. Ou, "Optimization design of a corrosion monitoring sensor by FEM for RC structures," IEEE Sensors Journal, vol. 11, no. 9, pp. 2111-2112, 2011.

[3] B. Elsener, "Corrosion rate of steel in concrete-measurements beyond the tafel law," Corrosion Science, vol. 47, no. 12, pp. 30193033, 2005.

[4] C. LeRose, "The collapse of the silver bridge," West Virginia Historical Society Quarterly, vol. 15, no. 4, 2001, http://www.wvculture.org/history/wvhs/wvhs1504.html.

[5] CBC.ca, "Former Quebec premier to head probe into overpass collapse," 2006, http://www.cbc.ca/news/canada/story/2006/ 10/02/laval-montreal.html.

[6] R. Afifah and Latief, Struktur Wahana Atlantis Dikaji Ulang, 2011, http://megapolitan.kompas.com/read/2011/09/28/ 12185069/Struktur.Wahana.Atlantis.Dikaji.Ulang.

[7] B. Woodard, Apartment Building Cited Several Times Before Porch Collapse Injured Man, 2015, http://www.dnainfo.com/ chicago/20150327/west-rogers-park/apartment-building-citedseveral-times-before-porch-collapse-injured-man.

[8] K. Hornbostel, C. K. Larsen, and M. R. Geiker, "Relationship between concrete resistivity and corrosion rate-a literature review," Cement and Concrete Composites, vol. 39, pp. 60-72, 2013.

[9] J. Gao, J. Wu, J. Li, and X. Zhao, "Monitoring of corrosion in reinforced concrete structure using Bragg grating sensing," NDT \& E International, vol. 44, no. 2, pp. 202-205, 2011.

[10] Z. W. Wang, M. Zhou, G. G. Slabaugh, J. Zhai, and T. Fang, "Automatic detection of bridge deck condition from ground penetrating radar images," IEEE Transactions on Automation Science and Engineering, vol. 8, no. 3, pp. 633-640, 2011.

[11] H.-W. Song and V. Saraswathy, "Corrosion monitoring of reinforced concrete structures-a review," International Journal of Electrochemical Science, vol. 2, no. 1, pp. 1-28, 2007.

[12] M. Ridha, S. Fonna, S. Huzni, and A. K. Ariffin, "Corrosion risk assessment of public buildings affected by the 2004 tsunami in Banda Aceh," Journal of Earthquake and Tsunami, vol. 7, no. 1, pp. 1-22, 2013.

[13] P. Marinier and O. B. Isgor, "Model-assisted non-destructive monitoring of reinforcement corrosion in concrete structures," in Nondestructive Testing of Materials and Structures, O. Büyüköztürk and M. A. Taşdemir, Eds., vol. 6 of RILEM Bookseries, pp. 719-724, Springer, New York, NY, USA, 2013.
[14] A. A. A. Hassan, K. M. A. Hossain, and M. Lachemi, "Corrosion resistance of self-consolidating concrete in full-scale reinforced beams," Cement \& Concrete Composites, vol. 31, no. 1, pp. 29-38, 2009.

[15] M. Ridha, K. Amaya, and S. Aoki, "Boundary element simulation for identification of steel corrosion in concrete using magnetic field measurement," Corrosion, vol. 61, no. 8, pp. 784791, 2005.

[16] M. Ridha, K. Amaya, and S. Aoki, "Multistep genetic algorithm for detecting corrosion of reinforcing steels in concrete," Corrosion, vol. 57, no. 9, pp. 794-801, 2001.

[17] K. Amaya and S. Aoki, "Effective boundary element methods in corrosion analysis," Engineering Analysis with Boundary Elements, vol. 27, no. 5, pp. 507-519, 2003.

[18] S. Aoki and K. Kishimoto, "Aplication of BEM to galvanic corrosion and cathodic protection," in Electrical Engineering Applications, C. A. Brebbia, Ed., vol. 7 of Topics in Boundary Element Research, pp. 65-86, Springer, New York, NY, USA, 1990.

[19] S. I. Kabanikhin, "Definitions and examples of inverse and illposed problems," Journal of Inverse and Ill-Posed Problems, vol. 16, no. 4, pp. 317-357, 2008.

[20] M. Pour-Ghaz, O. B. Isgor, and P. Ghods, "Quantitative interpretation of half-cell potential measurements in concrete structures," Journal of Materials in Civil Engineering, vol. 21, no. 9, pp. 467-475, 2009.

[21] S. Fonna, S. Huzni, M. Ridha, and A. K. Ariffin, "Inverse analysis using particle swarm optimization for detecting corrosion profile of rebar in concrete structure," Engineering Analysis with Boundary Elements, vol. 37, no. 3, pp. 585-593, 2013.

[22] S. Fonna, M. Ridha, S. Huzni, and A. K. Ariffin, "Comparison of GA and PSO in boundary element inverse analysis for rebar corrosion detection," Applied Mechanics and Materials, vol. 471, pp. 319-323, 2014.

[23] H. G. Wheat and Z. Eliezer, "Some electrochemical aspects of corrosion of steel in concrete," Corrosion, vol. 41, no. 11, pp. 640 645, 1985.

[24] D. Lesnic, J. R. Berger, and P. A. Martin, "A boundary element regularization method for the boundary determination in potential corrosion damage," Inverse Problems in Engineering, vol. 10, no. 2, pp. 163-182, 2002. 

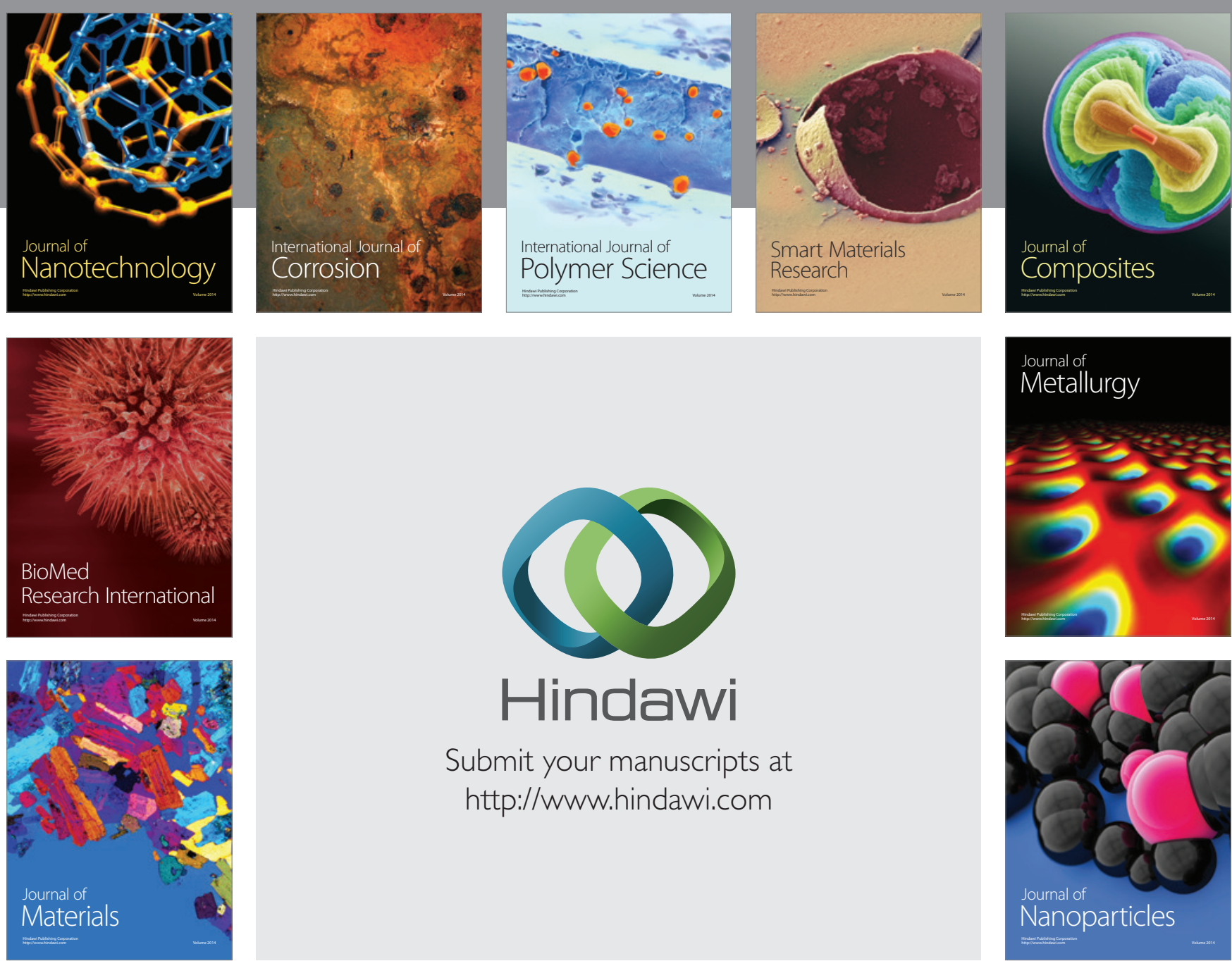

\section{Hindawi}

Submit your manuscripts at

http://www.hindawi.com

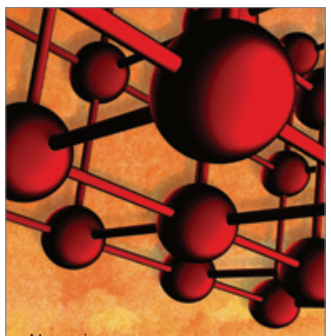

Materials Science and Engineering
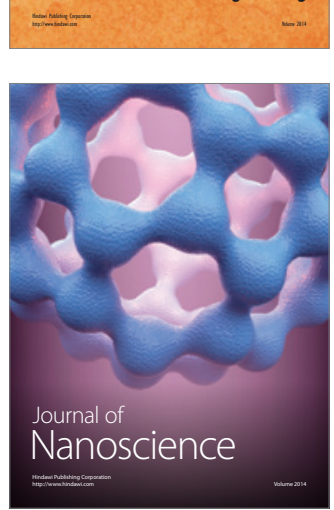
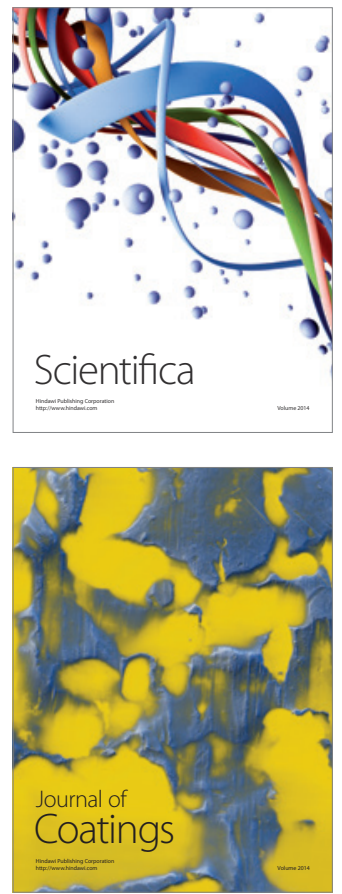
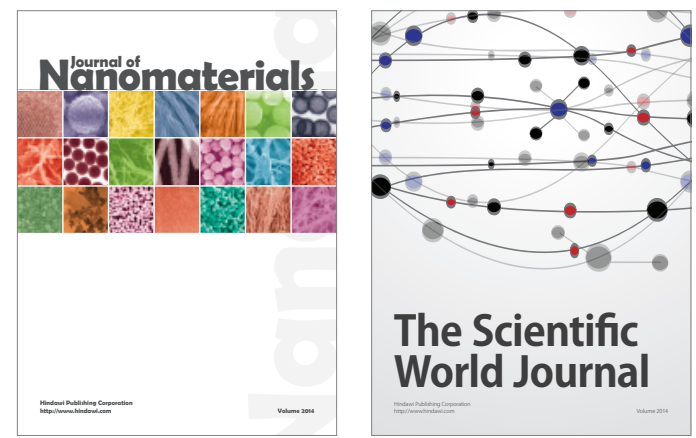

The Scientific World Journal
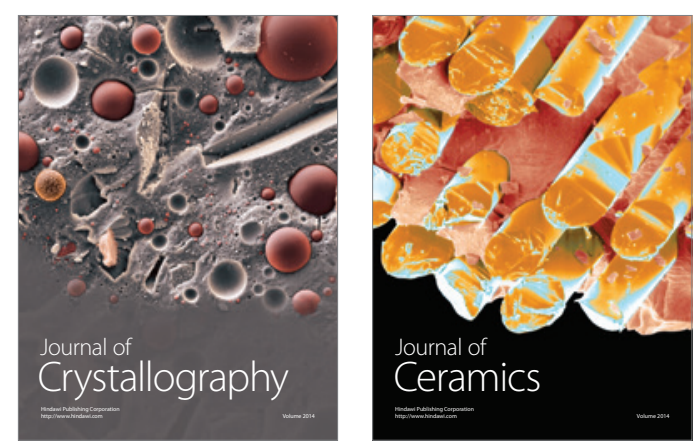
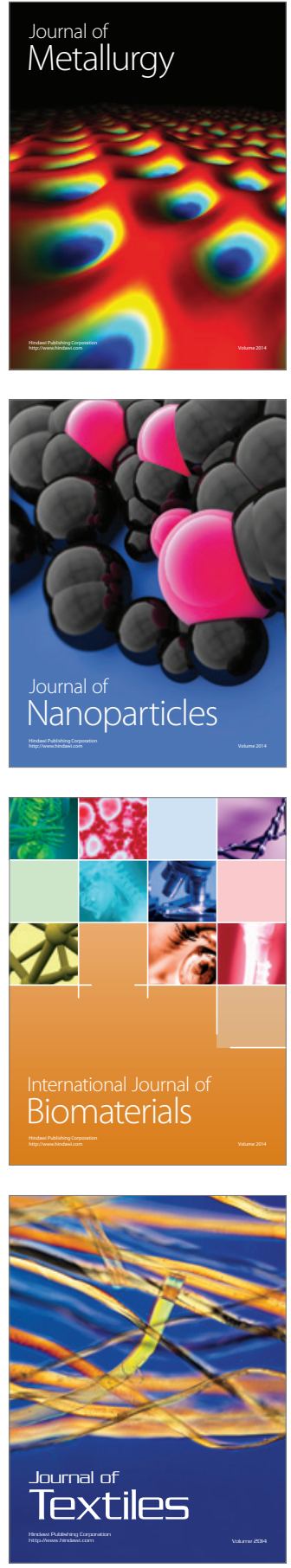